\title{
RECONOCIMIENTO DE PLACAS DE RODAJE EN AUTOMÓVILES, MEDIANTE EL PROCESAMIENTO DIGITAL DE IMÁGENES
}

\author{
Recognition of license plate in cars, by Digital Image Processing
}

\author{
Edith Paredes Choque: Alberto Cohaila Barrios ${ }^{2}$
}

\section{RESUMEN}

$\boxminus$ presente trabajo de investigación se enmarca en el procesamiento de placas de rodaje de vehículos chilenos mediante los analisis de imágenes. Para cumplir este propósito se requiere de una imagen de buena resolución, ubicación, orientación, iluminación etc. La imagen es captada mediante una cámara fotográfica. Dependiendo de la claridad de la imagen se procede a utilizar métodos y técnicas de procesado. La segmentación umbralización, la binarización y el filtrado son herramientas que permitirán el reconocimiento de los caracteres de la placa de rodaje. Uno de los tipos de placas de rodaje chileno está compuesto de cuatro letras separadas con un símbolo seguida de dos números. $日$ método utilizado para el procesado de la imagen es el Otsu. Se elabora el algoritmo en el programa Matlab para su tratamiento. Posteriormente estos caracteres extraídos son guardados en un Bloc de Notas.

Palabras claves: imagen, binarización, segmentación, resolución, umbralización.

\section{ABSTRACT}

The present research work is part of the processing of Chilean vehicle chassis through the analysis of images. To fulfill this purpose requires an image of good resolution, location, orientation, lighting etc. The image is capturad by a camera. Depending on the clarity of the image proceed to use methods and techniques of processing. The segmentation thresholding, binarization and filtering are tools that allow the recognition of the characters of the plate. One of the types of Chilean taxi plates is composed of four separata letters with a symbol followed bytwo numbers. The method used forthe image processing is the Otsu. The algorithm is elaborated in the Matlab program far its treatment. These extractad characters are then saved in a Notepad.

Keywords: image, binarization, segmentation, resolution, thresholding.

\section{INTRODUCCIÓN}

La historia del POI (procesamiento digital de imágenes) se remonta a la década de los '60 y está directamente ligada con el desarrollo y evolución de las computadoras. Su progreso ha ido de la mano con el desarrollo de las tecnologías de hardware, ya que requiere un alto poder y recursos computacionales para almacenar y procesar las imágenes. De igual manera el desarrollo de los lenguajes de programación y los sistemas operativos han hecho posible el crecimiento continuo de aplicaciones relacionadas al procesamiento de

\footnotetext{
1 Msc. con mención en Gestión Ambiental $y$ Desarrollo Sostenible.

Docente de la Facultad de Ciencias - Universidad Nacional Jorge Basadre Grohmann - Tacna Perú

2 Msc. en Computación e Informática.

Docente de la Facultad de Ciencias - Universidad Nacional Jorge Basadre Grohmann - Tacna Perú
} 
imágenes, tales como: imágenes médicas, satelitales, astronómicas, geográficas, arqueológicas, biológicas, aplicaciones industriales, entre otras. (Parker \& Pavol, 2004)

La necesidad de identificar un vehículo está relacionada con el reconocimiento de las placas correspondientes; esto se hace necesario debido a que se podría tener un mejor control en casos de infracciones, así como robos o accidentes vehiculares. La seguridad ciudadana está ligada con estos factores, por lo que el desarrollo de un sistema automático de reconocimiento de placas vehiculares ayudaría a tener una ciudad más segura.(Salazar\&Marcio, 2014).

El controlar las placas de rodaje de vehículos en forma personalizada es tedioso y costoso. Requiere de un controlador que esté constantemente observando el paso de los vehículos y anotando las placas para posteriormente ser analizadas y determinar el resultado ya sea verificando la infracción, o bien la cantidad de vehículos turistas que ingresan a la ciudad o tal vez verificar si los vehículos son robados.

Por ello se plantea un control automático mediante el procesado digital de imágenes que permitirá capturar la imagen en el tiempo, mediante una toma fotográfica para que este sea procesado digitalmente. En la actualidad existen muchas aplicaciones de software que permiten el procesamiento digital de imágenes, mucho de este, utiliza técnicas o algoritmos que son bien conocidos por la comunidad que trabaja en ello, pero otros utilizan sus propias variantes 0 técnicas nuevas que están poco documentadas.

\section{Objetivos}

- Capturar la imagen

- Mejorar la apariencia de la imagen obtenida del objeto.

- Desarrollo de algoritmos para la captación de imágenes.

- Analizar y comprender las técnicas básicas de segmentación de imágenes.

- Utilizar herramientas computacionales para el manejo de imágenes.

- Procesar los datos de la imagen obtenida del objeto "placa".

\section{MATERIAL Y MÉTODO}

\section{Procedimiento}

- Se buscan imágenes de placas de rodaje chilenas de diferentes posiciones y tomadas con cámaras de diferentes resoluciones.

- Se ubica la mejor toma para el procesado de la imagen; para que el programa responda requiere de una toma ubicada en una ubicación exacta y precisa. Esto hará que la programación no se haga tediosa.

- Se utiliza el programa Matlab para el procesado de la imagen.

- Se guarda la imagen a colores de la placa de rodaje chilena con extensión JPG.

- Se convierte la imagen a en color gris.

- Se corta la región de interés de la imagen completa ubicando tan solo la zona de interés como es en este caso la placa de rodaje.

- Binarizamos la imagen.

- Hacemos la conversión a binaria de la imagen cortada con el umbral óptimo.

- Aplicamos técnica de la morfología binaria.

- Aplicamos el método de Otau.

- Aplicamos la técnica de segmentación.

- Filtramos la imagen.

- Se determina el tamaño del carácter recortado.

- Se utiliza el block de notas para depositar el carácter extraído.

\section{Evaluación de las imágenes}

\subsection{Evaluación de imágenes de placas Chilenas}

Se evalúa placas chilenas bajadas de internet de diferente toma y números para su evaluación.

\subsection{Evaluación}

Visto los diferentes tipos de placas chilenas se procede a la evaluación. 
Se muestran diferentes fotos de toma de placas de rodaje de autos chilenos, en la cual se va a tener que tomar en cuenta su posición, ubicación, iluminación y color entre otros. Tipo de cámara que se utiliza es decir ver sus características. Como evaluación de las imágenes mostradas veremos cuál de ellas es la más adecuada para el procesamiento de imágenes

La imagen muestra la placa de rodaje chilena con cuatro letras separadas de un guion, enseguida viene dos números que los separa de un símbolo. La toma es frontal.

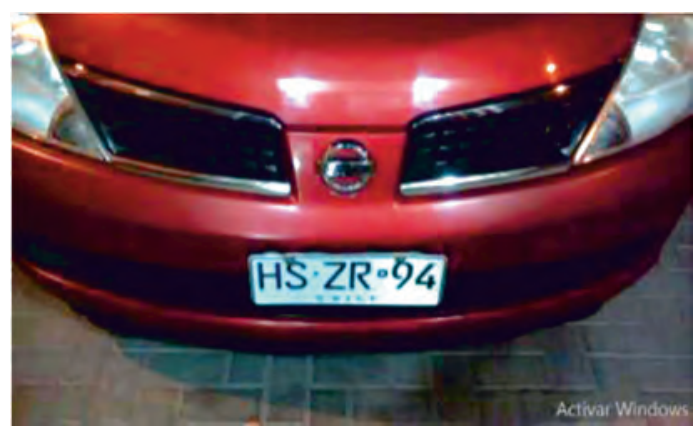

Figura 1: Imagen de placa de rodaje Fuente: propia

En las diferentes fotografías vistas de las imágenes de placas de rodaje, se pueden encontrar diferentes casos a tomar en cuenta en el momento de desarrollar los programas. Podemos ver la inclinación de las imágenes, la poca claridad de los números de la placa de rodaje, la distancia, la suciedad de las placas, el mantenimiento y la antigüedad de las mismas.

Las placas de rodaje vistas son en algunos casos compuesto de dos letras del alfabeto y cuatro números separados de a dos. En otros casos observamos que son de cuatro letras del alfabeto en forma de mayúscula, separados de a dos con un punto, seguidamente un aro con fondo de estrellas de 5 puntas separa dos números.

Otro detalle que podemos observar en la toma de las diferentes imágenes es en cuanto a color de las placas de rodaje, observamos que en algunos casos el fondo es de color blanco, en otros casos de color anaranjado y los números como las letras resaltado en color negro.

Todas las observaciones realizadas hasta el momento se tienen que considerar para poder realizar el algoritmo del programa que permitirá procesar la imagen y obtener como resultado la detección de los números en formato digitalizado.

Para las prueba con el algoritmo se utiliza la figura 1. Las propiedades de la imagen son como muestran en el siguiente cuadro.

La figura 2, muestra la tabla propiedades de la imagen de la placa de rodaje

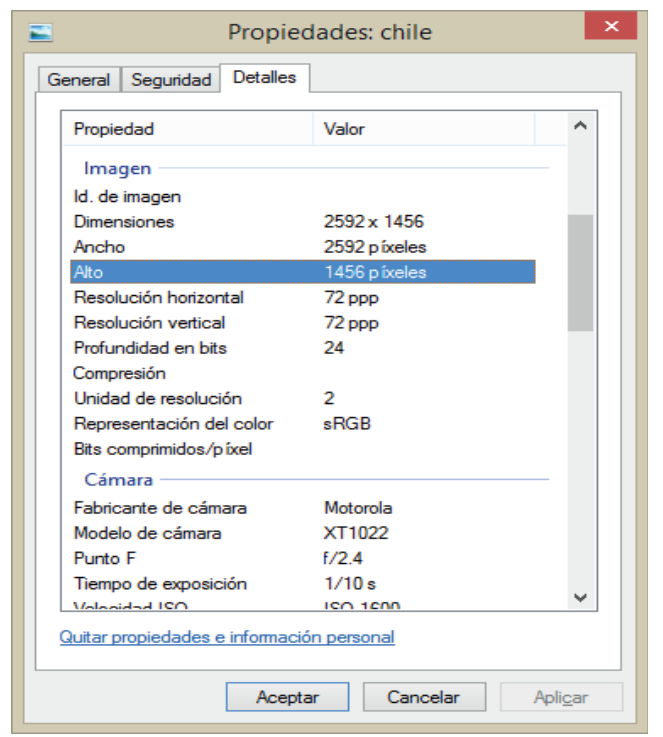

Figura 2: Propiedades de la imagen de la placa de rodaje

Fuente: Propia

\section{RESULTADOS}

Al convertir la figura 1 a escala de grises, seleccionamos el número de placa de rodaje.

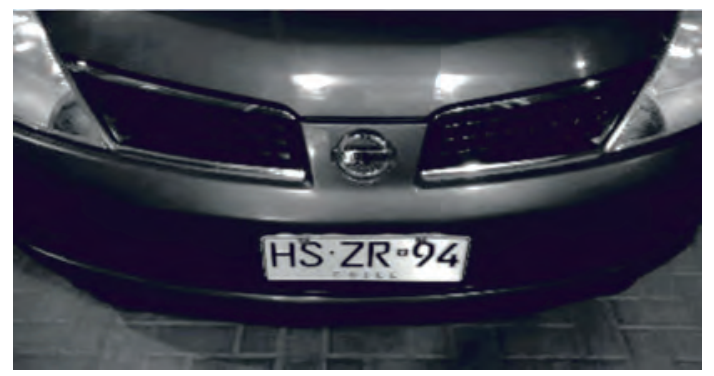

Figura 3: Imagen escala de grises Fuente: Propia

Al seleccionar la imagen de la figura 1, obtenemos la siguiente figura recortada donde solo se observa la placa de rodaje. Esto lo hace con el programa creado en Matlab. Véase Anexo (código del programa del reconocimiento de la placa de rodaje).

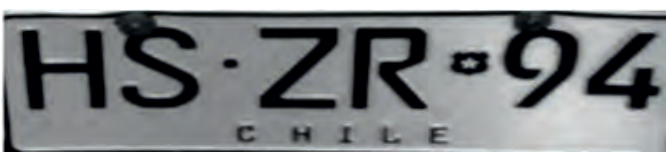


Figura 4: Imagen recortada escala de grises Fuente: Propia

La figura muestra la binarización

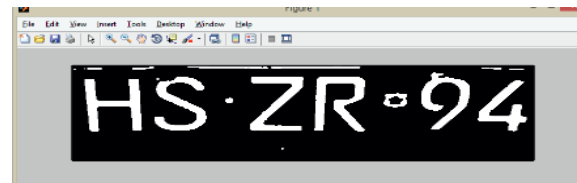

Figura 5: Imagen recortada escala de grises binarización.

Fuente: Propia

Aplicando el método de Otau, la técnica de segmentación y el filtrado se obtiene la siguiente imagen.

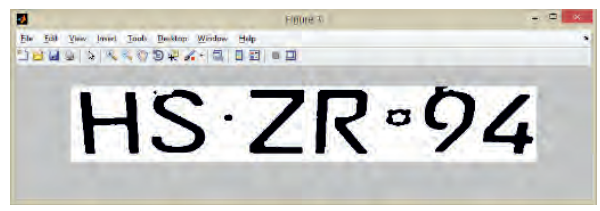

Figura 6: Imagen recortada escala de grises aplicando método Otau.

Fuente: Propia

Al correr el programa muestra la independización de los caracteres, para posteriormente ser guardado en una base de datos que será el block de notas.
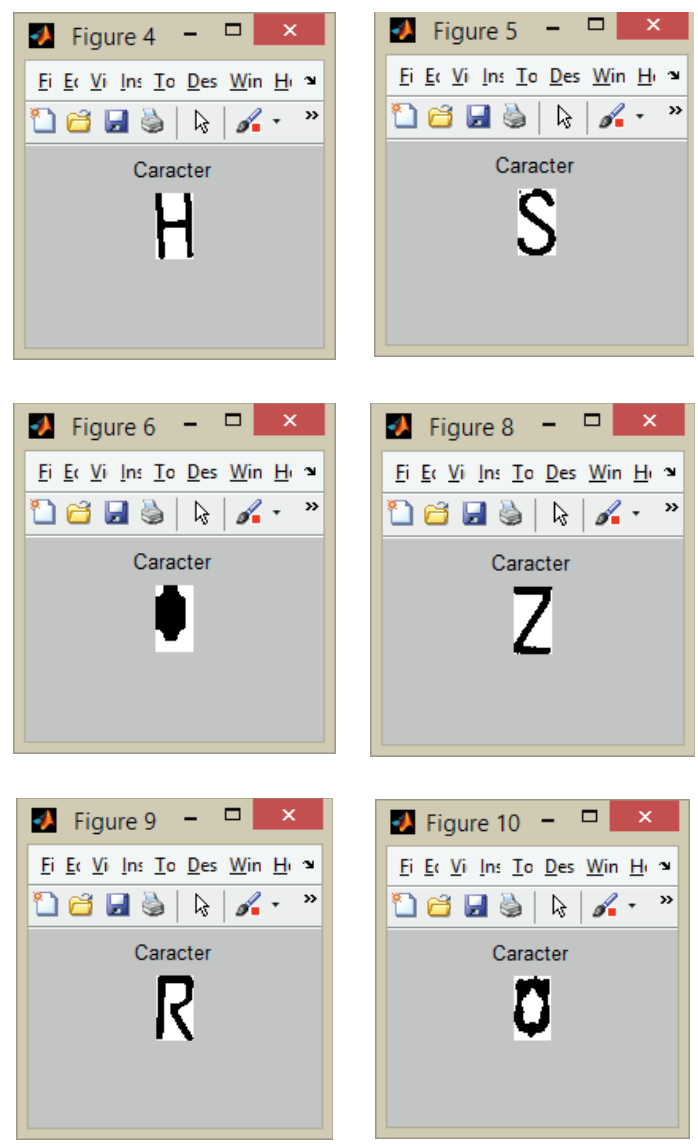

Figura 7: Extracción de los caracteres de la placa de rodaje chilena.

Fuente: Propia

El bloc de notas funciona como una base de datos donde se depositó los caracteres de la placa de rodaje, base de datos. Figura 7 .

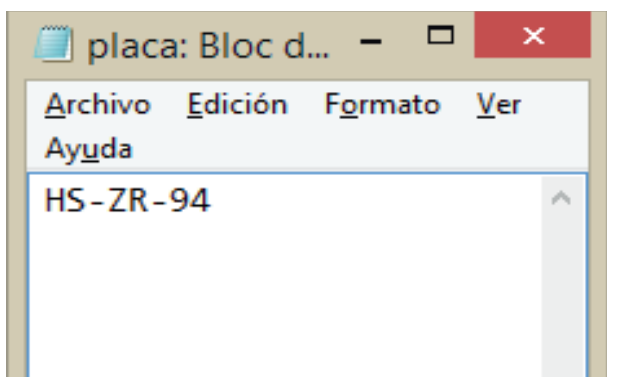

Figura 8: Extracción de los caracteres en el Bloc de Notas.

Fuente: Propia

\section{DISCUSIÓN}

Existen numerosos espacios de color en la actualidad. La gran mayoría de ellos se han desarrollado para aplicaciones específicas. El empleo del modelo RGB para el procesamiento de imágenes es útil cuando estas vienen expresadas en términos de los tres planos de colores. Alternativamente, la mayoría de las cámaras en color que se usan para adquirir imágenes digitales utilizan el formato RGB, lo que hace, si cabe, más interesante este formato. El uso de los modelos de color CMY y CMY-K está concentrado en los sistemas de impresión. En visión por computador raramente son usados. El modelo cromático XYZ es independiente de dispositivo y se emplea en aplicaciones en las que la representación del color no dependa de la naturaleza del equipo o hardware. El modelo CIELAB, como el CIELUV, es independiente de dispositivo. Al igual que en los sistemas industriales de medición del color, el sistema CIELAB es utilizado en aquellas aplicaciones que requieran una medida precisa de la distancia perceptual entre dos colores (Ortiz, 2006). Para nuestro procesado de placas de rodaje utilizamos el modelo RGB.

En el campo de la segmentación, en la actualidad, existe un gran número de investigadores que están desarrollando nuevas técnicas para poder abordar problemas cada vez más complejos, que hace unos años no se podía resolver. Algunas de las técnicas son la segmentación por bordes y la segmentación por umbralización. El proceso de umbralización basado en el histograma, consiste en agrupar los píxeles según sus niveles de intensidad luminosa. La segmentación en este caso, consiste en 
encontrar el umbral necesario para realizar una binarización que separe al objeto (poniéndolo en blanco) del fondo (en negro viceversa). (González et al, 2006).

La umbralización es una técnica de segmentación ampliamente utilizada en las aplicaciones industriales. Se emplea cuando hay una clara diferencia entre los objetos a extraer respecto del fondo de la escena. Los principios que rigen son la similitud entre los píxeles pertenecientes a un objeto y sus diferencias respecto al resto. Por tanto, la escena debe caracterizarse por un fondo uniforme y por objetos parecidos. El método de Otsu en la umbralización fue uno de los mejores métodos de selección de umbral para imágenes del mundo real. La importancia del método de Otsu radica en que es automático, es decir, no necesita supervisión humana ni información previa de la imagen antes de su procesamiento. (UNQ, 2005).

Otras técnicas utilizadas para el procesamiento de placas de rodaje vehiculares mediante las redes neuronales (Hakan et al, 2008).

El sistema de reconocimiento de placas vehiculares está basada en el procesamiento de imágenes y el entrenamiento y evaluación de patrones. Las redes neuronales. Placas de rodaje mexicanas. (Delgado J, 2010).

Las técnicas y métodos elegidos para el procesamiento de imágenes, se da en la aplicación en diferentes campos, el método en el procesado dependerá del tipo de imagen a utilizar. En nuestro caso utilizamos el método de Otsu para aclarar imágenes borrosas de placas de rodaje vehiculares.

\section{CONCLUSIONES}

Se captura la imagen con una cama fotográfica de alta resolución. Se elige una imagen de placas de rodaje chilena de buena resolución, orientación, intensidad luminosa.

Para mejorar la apariencia de la imagen obtenida del objeto se utiliza el método de Otsu. Se comprueba la robustez o capacidad del método de Otsu para encontrar un umbral óptimo.

Se desarrolla el algoritmo para el procesado de la imagen utilizando el programa Matlab.

Se utiliza la técnica de Umbralización para la segmentación de las imágenes. Esto se da cuando la imagen tiene sombra.

La herramienta computacional utilizada para el procesado de la imagen desde la captura hasta obtener el número de placa de rodaje en el Bloc de notas, es el programa Matlab.
Se procesa la imagen de placas de rodaje de vehículos chilenos y los caracteres reconocidos son guardados en una base de datos, en este caso en el bloc de Notas

BANKMAN (2000), I. N. Handbook of MEDICAL IMAGING. PROCESSING AND ANALYSIS. ISBN 012-077790-8, USA: Academic Press, 2000.

BUOVIK, A. (2000) Handbook of Image and Video Processing. Principles and Applications. ISBN 0-12119790-5, USA: Academic Press, 2000.

DELGADO JOSÉ (2010) Reconocimiento de Placas Vehiculares. Tesis para obtener el grado académico de maestro en Ciencias de ingeniería microelectrónica.

GARCÍA (2008), Visión Artificial y Procesamiento Digital de Imágenes usando Matlab Ibarra Ecuador 2008.

GONZÁLEZ ETAL (2006) Técnicas y Algoritmos Básicos de Visión Artificial. Material de ingenierías $\mathrm{N}^{\circ}$ 24. 2006

GONZÁLEZ, R. C., R. E. (2006) Woods. Digital Image Processing Using MATLAB. ISBN 81-7758-898-2, USA: Pearson Educational, 2006.

JAHNE, B. (2002) Digital Image Processing. 5th and extended edition. ISBN 3-540-67754-2, Germany: Springer.

J.R. PARKER \& PAVOL FEDERL an Approach To Licence Plate Recognition. Laboratory For Computer Vision Computer Graphics Laboratory University Of Calgary

SALAZAR M. M. B. (2014). Desarrollo de un algoritmo para la localización automática de placas vehiculares peruanas usando técnicas de procesamiento de imágenes. Lima - Perú 2014

Oppenheim, A. V. y Schafer, R.M. digital signal processing. (1975) Englewood Cliffs,NJ:Prentice-Hall, 1975.

PETROU, M., P. BOSDOGIANNI. (1999). Image Processing: the fundamentals. ISBN 0-471-998834,USA: John Wiley and Sons, 1999.

LAORDEN (2012)Descripción, Comparación $Y$ Ejemplos De Uso De Las Funciones De La Toolbox De Procesado Digital De Imágenes De Matlab.

Universidad Nacional de Quilmes - Ing. en

Automatización y Control Industrial

Cátedra: Visión Artificial Octubre de 2005

OPPENHEIM, A. V.; WILLSKY, SCHUSTER. (1997)

SEÑALES Y SISTEMAS, 2da. Edición. A Simon \&

Company: Prentice Hall.

JACKSON, L.B (1991) Signal and Transform. Addison-

Wesley, Reading, M.A.,1991

MC GILLEN, C.D. Y COOPER, G.R.,

( 1984 )

Continuos And Discrete Signal And Sistem Analisis. Holt, Rinehart and Winston, New York, 2da. Ed.

ROBERTS, R.A. Y MULLIS , C.T. (1987) DIGITAL SIGNAL PROCCESING. Addison - Wesley, Reading, MA,

HAKAN CANER, H,SELKUT GWCIM, ALI ZIYA ALKAR (2008). Efficient Embedded Neural-NetworkBased License Plate Recognition System.

\section{Correspondencia}

Edith C. Paredes Choque

Ciudad Universitaria "Los Granados"

Av. Miraflores s/n.Tacna. Perú

ecparedesc@hotmail.com 